\title{
Kristlikud ja mittekristlikud usuühendused Eestis 1990. aastatel
}

\section{Jaanus Plaat}

Küsimusele, kui palju on Eesti Vabariigis erinevaid uskkondi ja usuliikumisi, on raske täpselt vastata, kuna kõigi Eestis 1990. aastatel tegutsenud usuühenduste kohta pole ametlikku statistikat. Samuti napib vastavaid uurimusi. Viimast korda peeti täpsemat arvestust legaalsete ja põranda all tegutsenud uskkondade üle Nõukogude Eesti perioodil, 1945.-1990. aastatel Eesti usuühenduste tegevust kontrollinud Usukultusasjade Nõukogu ENSV volinike poolt.

Juba Nõukogude okupatsiooni esimesel aastal (1940-1941) keelati paljude uskkondade ja usuorganisatsioonide tegevus. 1940. aastate teisel poolel viidi Eestis läbi koguduste ümberregistreerimine, mille käigus keelustati veel mitmed senitegutsenud usuühendused. Kuni 1980. aastateni tegutsesid seaduslikult, s.t ametlikult registreerituna vaid kaheksa kirikut ja kogudusteliitu: luteri, õigeusu, katoliku ning metodisti kirikud, juudi, vanausuliste ja seitsmenda päeva adventistide kogudused ning erinevaid vabakogudusi koondanud Evangeeliumi Kristlaste ja Baptistide Koguduste Liit. 1980. aastate esimesel poolel registreeriti ka osa illegaalsetest nelipühikogudustest. Usukultusasjade Nõukogu voliniku arhiivi (UNVA) andmetel tegutses Nõukogude Eestis 1987. aastaks kokku 359 registreeritud kogudust. Koguduste ja erinevate uskkondade arv hakkas kasvama alates 1980. aastate lõpust, seoses pöördeliste sündmustega Eesti ühiskonnas, mis viisid Eesti Vabariigi taasiseseisvumiseni 1991. aastal.

Aastal 1990 loodi likvideeritud usuasjade voliniku institutsiooni asemele Kultuuriministeeriumi osakonnana tegutsenud usuasjade talitus, mis 1993. aastal viidi üle Siseministeeriumi alluvusse ja reorganiseeriti usuasjade osakonnaks. Selle riigi ja usuorganisatsioonide vahelisi suhteid koordineeriva ametkonna üheks ülesandeks on Eestis tegutsevate kirikute, koguduste ja koguduste liitude põhikirjade registreerimine ning Eesti kirikuregistri pidamine. 1993. aastal kinnitati «Eesti kirikute, koguduste ja koguduste liitude registri põhimäärus», mille järgi «kirikuregistri asutamise ja pidamise eesmärgiks on tõese teabe saamine kõigi Eesti territooriumil tegutsevate kirikute ja koguduste ning nende allasutuste ja ühenduste kohta» (Riigi Teataja Lisa, nr 16, 1993). ${ }^{1}$ Eestis tegutsevad usuühendused saavad seadusliku kinnituse, kui nad registreerivad end Siseministeeriumi usuasjade osakonnas ning nende põhikirjad vastavad nõuetele. Seisuga 01. 01. 2000 oli Siseministeeriumis arvel 518 kogudust. Neist 60 ei kuulunud ühtegi Eesti 15 st kirikust või koguduste liidust. Lisaks olid registreeritud Pühtitsa õigeusu nunnaklooster ja mitmed Rooma-Katoliku Kiriku ordud. Samuti pole selle 518 hulka arvatud 35 usuorganisatsiooni või seltsi, mis olid Siseministeeriumis registreeritud aastatel 1994-1996 «Mittetulundusühingute ja nende liitude seaduse» alusel. $\underline{\text { ? }}$ Alates 1996. aastast on viimaseid registreeritud linnakohtute registriosakondades.

Siiski on andmed Eestis 1990. aastatel tegutsenud usuühenduste kohta lünklikud, kuna mitte kõik usuühendused pole registreeritud. Ülevaate registreeritud Eesti usuorganisatsioonidest annab usuasjade osakonna töötajate Ilmo Au ja Ringo Ringvee koostatud miniteatmik Kirikud ja kogudused Eestis. Käesolevas lühiülevaates on lisaks usuasjade osakonna andmetele toetutud ka nõukogudeaegse usuasjade voliniku arhiivile, erinevate uskkondade endi statistikale ja teistelegi allikatele ning käsitlustele. ? $^{3}$ Piirdutud on eelkõige olulisemate registreeritud ja autorile teadaolevate registreerimata usuühendustega, mis on 1990. aastatel Eestis tegutsenud. Esmalt on käsitletud neid vanemaid uskkondi, mis tegutsesid ka eelnenud nõu- 
kogude perioodil (olgu ametlikult või illegaalselt). Seejärel on loetletud uusi uskkondi ja usuliikumisi, mis levisid Eestis alates 1980/1990. aastate vahetusest. Neist osa oli Eestis esindatud ka enne 1940. aastat, kuid Nõukogude okupatsiooni ajal pole nende organiseeritud tegevusest andmeid. Lõpetuseks on toodud valik nendest Eestis tegutsenud usuorganisatsioonidest, mis pole enamasti seotud mingi kindla uskkonnaga.

\section{Enne 1980. aastate lõppu tegutsenud usuühendused tänases Eestis}

Enamik tänases Eesti Vabariigis tegutsevatest erinevatest uskkondadest ja liikumistest levis Eestisse alles piiride taasavanedes, 1980. aastate lõpul - 1990. aastate algul, mil rahvusliku taasärkamisliikumise laineharjal avastasid paljud (uuesti) religiooni, mis nõukogude perioodi võitleva ateismi ja sekularisatsiooniprotsessi edusammude tõttu oli enamikule eestlastele võõraks muutunud. Suuresti elavnes ka paljude senitegutsenud uskkondade tegevus. See rahva taasärganud huvi usuasjade vastu oli paljuski tingitud ka oma «juurte otsimise» ja seni keelatu avastamise lustist. Nn kirikubuum jäi siiski lühiajaliseks ning suur osa 1980. aastate lõpul ja 1990. aastate algul kirikute-kogudustega liitunutest on tänaseks neist taas eemale jäänud.

Vanadest uskkondadest suurenes 1980/1990. aastate vahetusel kõige enam Eesti Evangeelse Luterliku Kiriku mõju. Siiski on alates 16. sajandist Eesti kristlikus usuelus domineerinud luterliku kiriku tegeliku liikmeskonna arv 20. sajandi lõpuks jäänud väga väikeseks, olles samas jätkuvalt Eesti suurim. 1997. aastal oli EELK annetajaliikmete osakaal Eesti elanikest vaid 3,6\% ning neid oli juba üle viie korra vähem kui 1937. aastal. Seejuures on EELK annetajaliikmeskond alates 1990. aas-

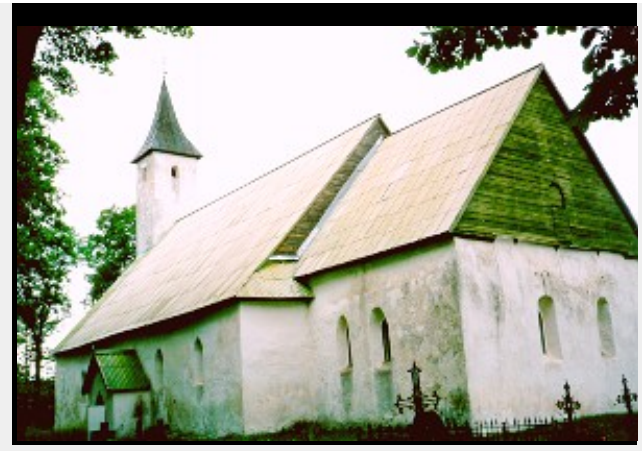

Noarootsi kirik Läänemaal tate keskpaigast pidevalt vähenenud. 1999. aastal oli EELK Konsistooriumi andmetel alles veel 48526 annetajaliiget ning kogudusi oli EELK-1 166. $\stackrel{4}{ }$

Seoses Eesti taasiseseisvumisega on jälle juriidilise isiku õigused saanud luterliku kiriku sees tegutsev Eesti Evangeelne Vennastekogudus. Just vennasteliikumine, mis jõudis Eestisse üsna varsti pärast tekkimist Saksamaal 1727. aastal, pani aluse kohaliku maarahva sisulisele kristianiseerumisele, millega polnud seni hakkama saanud ei katoliku ega luteri kirikud. Oma arvulise lae saavutas liikumine meil 19. sajandi keskel, mil vennastekogudusse kuulus umbes 50000 inimest (Philipp 1974: 219-220). 2000. aastaks oli vennastekoguduse liikmeid Eestis alles jäänud vaid 150 ringis.

Liikmete arvult teine konfessioon Eestis on jätkuvalt õigeusk, mis levis eestlaste seas laiemalt seoses 1840. aastatel eriti Lõuna-Eestis ja saartel alanud massilise luterlaste õigeusku siirdumisega. 1990. aastatel registreeriti taas Eesti Apostlik-Õigeusu Kirik, mis oli loodud 1920. aastatel ja

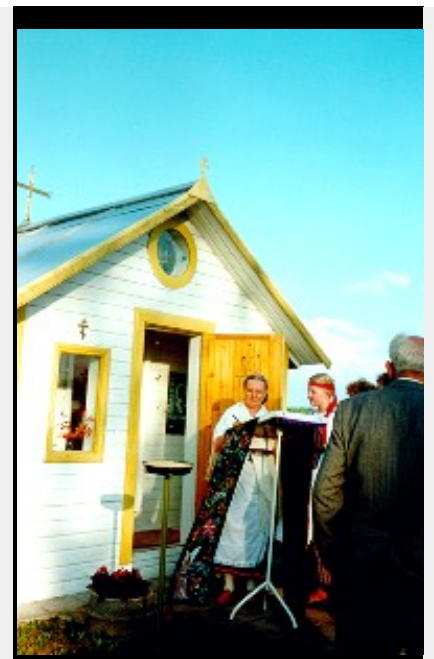

Treski tsässon Setumaal 
oli sunnitud nõukogude perioodil oma tegevust jätkama eksiilis. EAÕK valdavalt eestikeelsed kogudused läksid 1996. aastal jälle Konstantinoopoli patriarhaadi koosseisu. Seoses sellega on Eesti õigeusu kogudused 1990. aastatel kaheks jagunenud, kuna enamik venekeelseid kogudusi (valdavalt hilismigrantidest liikmeskonnaga) on jäänud truuks Moskva patriarhaadile ning teravalt on esile kerkinud vastuolud õigusliku järjepidevuse ning õigeusu kiriku varade küsimuses. 2000. aastaks oli piiskop Stefanuse juhitavas Konstantinoopolile alluvas EAÕK-s 58 kogudust umbes 18000 liikmega. Moskva patriarhaadiga oli seotuks jäänud paarkümmend registreerimata õigeusu kogudust. Siseministeeriumis registreeritud olid vaid Aleksander Nevski kogudus Tallinnas ja Pühtitsa nunnaklooster, mis on otseselt Moskva patriarhi alluvuses. Õigeusu kloostritest tegutseb edasi ka pärast Teist maailmasõda Venemaaga liidetud territooriumile jäänud Petseri mungaklooster.

1990. aastatel tegutsenud ülejäänud uskkondade liikmeskond on tunduvalt väiksem kui luteri ja õigeusu kirikutel. Neist üks arvukamaid on Eesti Vanausuliste Koguduste Liit, kuhu kuulub 11 kogudust. Alates 17. sajandi lõpust Peipsi järve ümbruskonnas elanud vene vanausulistel on peale Peipsi piirkonna oma kogudused veel Tartus ja Tallinnas.

Valdavalt linnades tegutsevad Rooma-Katoliku Kiriku kogudused. Reformatsioonist kahekümnenda sajandi alguseni olid vähesed Eestis asuvad katoliiklased võõrpäritoluga isikud, kes osalt lahkusid Eestist II maailmasõja eel ja ajal. Eesti Vabariigis toimus siiski tagasihoidlikus ulatuses eestlaste pöördumine katoliiklusse, mis Nõukogude okupatsiooni lõppjärgus puhkes uuesti. Katoliku preestri Vello Salo andmetel oli Eestis 2000. aastaks kaheksa katoliku kogudust. Samuti on 1990. aastatel Eestis tegevust (taas)alustanud mitmed RoomaKatoliku Kiriku ordud, millest 2000. aastaks oli esindatud kaks meeste ordut (Opus Dei ja frantsiskaanid) ning kuus õeskonda (ema Teresa õed, birgitiinid, felitsiaanid, Kraliky õed, Pühima Vere ja Ukraina [idariituse] õed). $\underline{\underline{5}}$

19. sajandi viimasel veerandil Lääne-Eestis alguse saanud baptisti- ja priikogudused moodustavad koos 20. sajandi esimestel aastakümnetel Eestis levinud (endiste) evangeeliumi kristlaste ja nelipühikogudustega endiselt suurima liikmeskonnaga vabakoguduste liidu Eestis - Eesti Evangeeliumi Kristlaste ja Baptistide Koguduste Liidu, kuhu 01. 01. 1999 kuulus 85 kogudust (Aastakonverents 1999). Osa nelipühikogudusi on liidust iseseisvunud või liitunud 1990. aastate algul loodud Eesti Kristliku Nelipühi Kirikuga. Alates 19. sajan-

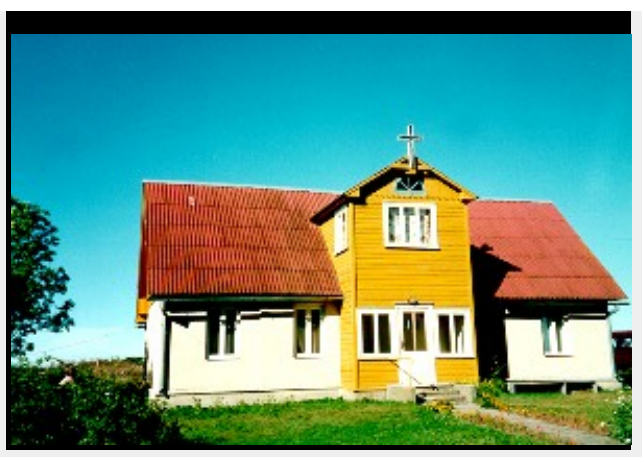

Harju baptistikoguduse palvemaja Hiiumaal di lõpust ja 20. sajandi algusest Eestis levima hakanud konfessioonidest tegutsevad tänases Eestis edasi ka Eesti Metodisti Kirik ja Seitsmenda Päeva Adventistide Eesti Liit, kus 2000. aastaks oli vastavalt 24 ja 18 kogudust.

Päris väikestest nõukogude perioodil illegaalsetena tegutsenud kogudustest on 1990. aastatesse teatud määral edasi kandunud (endiste) irvinglaste, urshanistide ja smirnovlaste tegevus. Juba 1880. aastatel Lääne-Eestis oma koguduse rajanud irvinglastega on ajalooliselt seotud 1990. aastatel jõudsalt levinud Uusapostlik Kirik Eestis. Sellel 1991. aastal Eestis (taas)asutatud kirikul on praeguseks 10 kogudust. Urshaniste on Eestis leidunud alates 20. sajandi teisest kümnendist ning osa neist kuulub praegu kogudusse, mis on registreeritud nime all «Evangeeliumi Kristlased Apostlite Vaimus» Tallinna Kogudus. Eestis 1932. aastal 
nime all «Ühendus Kristuses» registreeritud smirnovlaste tegevust jätkab arvatavasti 1990. aastatel registreeritud Kristlik Kogudus «Ühendus Kristuses».

Nõukogude Eestis illegaalselt tegutsenud uskkondadest on 1990. aastatel liikmeskonna kasvu poolest edukaimad olnud kristlusest lähtunud Jehoova tunnistajad, keda Nõukogude Eestis eriti karmilt taga kiusati. Nende tegevus oli Eestis alanud juba 1920. aastatel. $\mathbf{6}$ 2000. aastaks oli usuasjade osakonna andmeil Eesti Jehoova Tunnistajate Koguduste Liidus 11 registreeritud kogudust. Eesti Jehoova Tunnistajate Koguduste Liidu büroo andmetel olnud Eestis 2000. aastal koguni 46 Jehoova tunnistajate kogudust. Umbes pooled neist olid eesti- ja pooled venekeelsed. Enamikku neist 46-st võib siiski pidada pigem osakondadeks kui iseseisvateks kogudusteks.

Eestis on pikemat aega olemas olnud judaism ja islam vastavalt rahvusvähemuste religioonina. Nõukogude perioodil tegutses Eestis legaalselt üks juudikogudus. 2000. aastaks oli Eestis registreeritud kolm juudi kogudust: Eesti Juudi Kogudus, Tallinna Progressiivne Juudi Kogudus ja Narva Juudi Progressiivne Kogudus «Gineini». Lisaks oli 1996. aastaks registreeritud Eesti Juudi Koguduste ja Organisatsioonide Liit. Nõukogude Eestis mitteametlikult koos käinud islamiusulisi ei registreeritud kogudusena kuni 1989. aastani, mil UNVA andmeil registreeriti Tallinnas islamiusuliste (usuasjade voliniku järgi «tatarlaste-sunniitide») kogudus. See usuühendus kanti 1990. aastatel kirikute ja koguduste registrisse Eesti Islami Kogudusena. Viimasest lahku löönud Eesti Muhameedlaste Sunniitide Kogudus registreeriti 1995. aastal.

Järgnevalt on vaadeldud uskkondi, mille organiseeritud tegevusest nõukogude perioodil (enne 1980. aastate teist poolt) siinkirjutajal andmeid pole.

\section{Uued uskkonnad ja usuliikumised}

Registreeritud uskkonnad. Alates 1980/1990. aastate vahetusest on Eestis registreeritud paljud (Eestis) uued kristlikud konfessioonid ja kogudusteliidud. Neist üks esimesi oli 1980. aastate teisel poolel Eestis levinud «Elu Sõna» usuliikumine. UNVA andmetel registreeriti «Elu Sõna» kogudus 1989. aastal. 1994. aastal moodustati «Elu Sõna» kogudustest Eesti Kristlike Vabakoguduste Liit, kuhu kuulus 2000. aastaks seitse kogudust.

1990. aastate algul loodud uutest koguduste liitudest võib suurimana esile tõsta Eesti Kristlikku Nelipühi Kirikut (kuni aastani 1994 kanti nimetust Eesti Kristlik Kirik), kuhu 01. 01. 2000 seisuga kuulus usuasjade osakonna andmetel 38 kogudust. 1994. aastal eraldus EKNK-st Eesti Karismaatiliste Koguduste Liit (Teekäija, nr 4, 1995: 10). 1995. aastal oli selles liidus 24 kogudust (sh nn «Uue Elu» kogudused). Viimastest osa liitus 1996. aastal rajatud Eesti Karismaa-

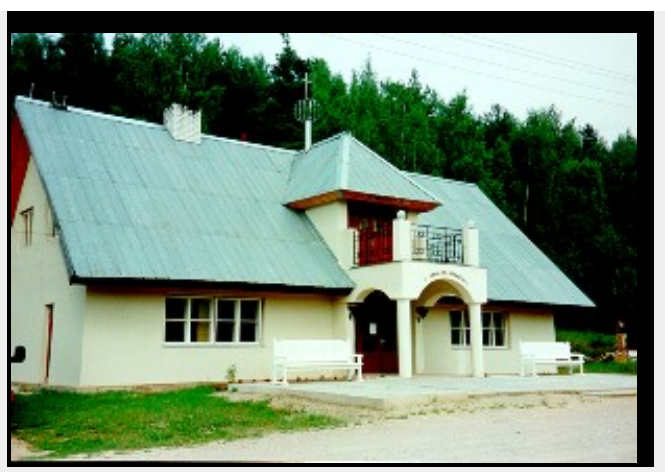

Eesti Karismaatiline Episkopaalkirik Põlvas tilise Episkopaalkirikuga, millega oli 1997. aastal seotud 22 kogudust või gruppi. Endisesse liitu olnud 1997. aastal alles jäänud 9 kogudust (Kui kristlik 1997: 19, 36). Seisuga 01. 01. 2000 kuulus usuasjade osakonna andmetel Eesti Karismaatilisse Episkopaalkirikusse 10 kogudust. Mitmed «Uue Elu» kogudused olid aga registreerunud iseseisvate üksikkogudustena. 
Teistest 1990. aastatel loodud ja kirikuregistrisse kantud kristlikest koguduste liitudest on mainimata veel Eesti Täisevangeelsete Koguduste Liit (viis kogudust 01. 01. 2000 seisuga) ja Eesti Evangeeliumi Kristlaste Nelipühilaste Koguduste Liit (kolm kogudust).

Siseministeeriumis 2000. aasta alguseks registreeritud ja liitudesse mittekuulunud 60-st üksikkogudusest oli valdav enamik rajatud 1990. aastatel ning suurt osa nendest võib pidada nelipühiliku usulaadiga vabakogudusteks (näiteks iseseisvad täisevangeelsed, «Uue Elu» ja nelipühikogudused). Üksikkogudustest võiks veel mainida Armeenia Apostliku Kiriku Eesti Kogudust ja Ukraina Kreeka-Katoliku Kiriku Tallinna Kogudust, kuhu kuuluvad vastavate rahvusvähemuste esindajad Eestis. Omapärasema õpetusega üksikkogudustest võib esile tõsta Eesti Kveekerlikku Püha Miikaeli Ilmutuse Kogudust.

Registreeritud oli ka üks mormoonide kogudus (Viimase Aja Pühade Jeesuse Kristuse Kiriku Tallinna Kogudus). ${ }^{7}$ Ida päritoluga mittekristlikest uskkondadest registreeriti 1990. aastatel eelkõige hinduismist ja budismist inspireeritud usuühendusi. Hinduismiga seotud uskkondadest registeeriti 1991. aastal Krishna Tunnetuse Tallinna Kogudus ja 1994. aastal Sathya Sai Baba Ühendus Eestis. Budistlikest kogudustest registreeriti 1993. aastal asutatud Eesti Budistlik Kogudus «Drikung Kagyu Ratna Shri Budistlik Keskus» ja 1997. aastal loodud Tiibeti Budismi Nyingma Eesti Kogudus. Eestlastest budiste on teada ka tunduvalt varasemast ajast. $\underline{8} \mathrm{Ka}$ esimestest Eesti bahaidest on andmeid juba nõukogude perioodist. Tallinna Baha'i Kogudus registreeriti 1995. aastal.

Uuenenud vormis on taastunud ka 1920.-1930. aastatel Eestis tegutsenud taarausuliste tegevus. 1995. aastal registreeriti nad Taarausuliste ja Maausuliste Maavalla Koja nime all. Sellesse usuühendusse kuulus 2000. aastaks kolm koda (kogudust).

Registreerimata usuühendused. Lisaks eespool toodud uskkondadele on Eestis 1990. aastatel tegutsenud veel terve rida organisatsioone ja liikumisi, mis pole usuasjade osakonnas kiriku, koguduse või koguduste liiduna registreeritud. Neist suur osa on Eestisse jõudnud alates 1980/1990. aastate vahetusest, peamiselt Skandinaavia maadest, Lääne-Euroopast ja USA-st. Osa järgnevalt loetletud usuühendustest on tänaseks oma tegevuse kas lõpetanud või liitunud eelnevalt nimetatud uskkondadega.

Kristlusega seotud usuorganisatsioonidest on Eestis 1990. aastate algul tegutsenud näiteks seitsmenda päeva baptistid, jehovistid,9 nn raskolniklased, Jumala Assamblee (Kolgata Templi Kirik), Hoosianna Kirik, uuslepinglased, Tõelise Jumala Kirik, Kristlaste Osaduse Kirik, Karismaatilised piibliringid jmt. Muudest religiooniga seotud ühendustest võiks mainida veel teosoofe, antroposoofe, kristosoofe, Kristlikku Teadust (Christian Science, mis jõudis Eestisse juba 1920. aastatel), Saientoloogiat, Urantia raamatu rühmi, mitmesuguseid uusajastulasi (New Age'i liikumises osalejaid) ja spiritualiste. Ida usunditest ja mõttemaailmast inspireeritud arvukatest usunditest/liikumistest, mis valdavalt küll läänemaade kaudu Eestisse on jõudnud, olgu mainitud budism, zenbudism, hinduism, Sry Chinmoy ja «südame jooga», mitmed teised jooga ning meditatsiooniga tegelevad liikumised jt usuga seotud ühendused (vt Leppik 1992). Eriti populaarseks sai Eestis 1990. aastate alguseks transtsen-

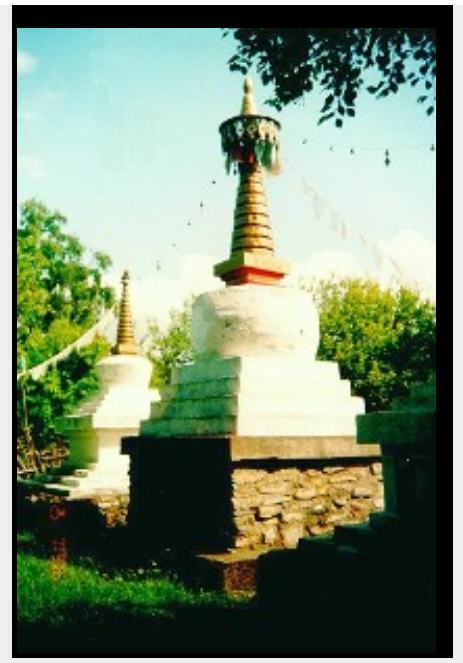

Stuupad budistlikus pühamus Ridala vallas Läänemaal 
dentaalse meditatsiooni liikumine. Mitmed idausunditest mõjustatud mõttevoolud olid peamiselt Eesti intellektuaalide seas levimas juba enne 1980. aastate lõppu. Ajakirjanduses on ilmunud teateid ka satanistlikest liikumistest (nn saatanakogudus, lutsiferiaanid, põrguinglid). Lisaks on 1990. aastatel tegutsenud paljud religiooniga seotud õpetajad, prohvetid, ravitsejad ja nõiad, kellest osal on välja kujunenud oma kindlam järgijaskond. Osa eespool nimetatutest ei ole moodustanud iseseisvaid kogudusi või on tegutsenud olemasolevate kirikute ja koguduste liikmete, samuti formaalselt mitte ühtegi usuühendusse kuuluvate inimeste hulgas.

\section{Muud religiooniga seotud organisatsioonid}

Lisaks oma õpetust ja usukombeid järgivatele uskkondadele ning usuliikumistele on alates 1980. aastate lõpust Eestis (taas)asutatud kümneid kristlikke organisatsioone ning seltse, mille peamisteks ülesanneteks on noorsoo-, sotsiaal- ja misjonitöö ning mis ei pea olema seotud konkreetse uskkonnaga. Reeglina on neid Eestis registreeritud mittetulundusühingute ja nende liitude, mitte kirikute ja koguduste seaduse alusel. Mitmed neist on Eestis tegutsenud juba enne 1940. aastaid, kui sellelaadsed organisatsioonid Nõukogude võimu poolt ära keelati. Pikema ajalooga kristlikest organisatsioonidest oli 1995. aastaks taasasutatud Eesti Piibliselts (piibliseltsid on Eestis tegutsenud alates 19. sajandi teisest kümnendist) ning 1920.-1930. aastatel Eestis tegutsenud ühingutest Päästearmee, Noorte Meeste ja Noorte Naiste Kristlikud Ühingud ning Eesti Sinine Rist. Uute organisatsioonidena rajati 1980. aastate lõpul ja 1990. aastatel näiteks Eesti Kristlik Ühendus, Eesti Evangelisatsiooni Allianss, Ühing «Gideon», Avatud Piibli Ühing, Eesti Kristlike Arstide Ühendus ja Kristlike Õdede Ühendus jmt. Asutati mitmeid kristlikke noorteühendusi (Eesti Kristlik Üliõpilaste Liit, Eesti Evangeelsete Üliõpilaste Ühendus, «Noored Missiooniga», «Operatsioon Mobilisatsioon», «Noored Kristusele», Noorteühendus Sool), samuti erinevaid misjoniorganisatsioone (Samaaria Eesti Misjon, Eesti Kristlik Misjon «Agape», Derek Prince'i Kristlik Misjon, Joosua Misjon jmt). Mitmeid samalaadseid organisatsioone on asutatud ka üksikute konfessioonide poolt. $\underline{10}$

Suurema konfessioonidevahelise ühendusena loodi 1989. aastal konsultatiivorganina Eesti Kirikute Nõukogu, kuhu kuulusid asutajaliikmetena luterlik ja õigeusu kirik, Eesti Evangeeliumi Kristlaste ja Baptistide Koguduste Liit, Eesti Metodisti Kirik ja Seitsmenda Päeva Adventistide Eesti Liit. Vaatlejatena osalesid katoliiklaste ning nelipühilaste esindajad. Rooma-Katoliku Kirik sai Eesti Kirikute Nõukogu täisliikmeks 1994. aastal. 1990. aastatel lisandusid vaatlejaliikmetena Eesti Apostlik-Õigeusu Kirik, Armeenia Apostliku Kiriku Eesti Kogudus ja Eesti Kristlik Nelipühi Kirik. Viimased kaks said hiljem täisliikmeteks. Seitsmenda Päeva Adventistide Eesti Liit jäi aga alates 1993. aastast vaatlejaliikme staatusesse (Kurg 1995: 115; Eesti Kirikute Nõukogu, nr 1, 1997; Estonia 1997: 4; Au \& Ringvee 2000: 114). 1995. aastal asutasid peamiselt nelipühiliku usulaadiga vabakogudused Eesti Kristlike Koguduste ja Ühingute Nõukogu.

Kahtlemata pole käesolevas lühiülevaates nimetatud kaugeltki mitte kõiki praegu Eestis tegutsevaid või 1990. aastatel tegutsenud liikumisi ja ühendusi, mis on kuidagi usu ja religiooniga seotud. Erinevate usuühenduste edasine põhjalikum uurimine väärib aga kindlasti vaeva, mõistmaks näiteks sedagi, et inimesed meie ümber mõtlevad, tunnevad ja usuvad palju erinevamalt, kui seda tihti arvatagi osatakse.

Autorifotod 


\section{Viidatud kirjandus ja allikad}

Aastakonverents 1999 = Aastakonverents 1999, 19.-20. veebruar. Eesti Evangeeliumi Kristlaste ja Baptistide Koguduste Liit. Tallinn.

Au, Ilmo \& Ringvee, Ringo 2000. Kirikud ja kogudused Eestis. Tallinn.

Eesti ettevõtete $1997=$ Eesti ettevõtete telefoniraamat 1998. Tallinn.

Eesti kristlikud $1997=$ Eesti kristlikud kogudused . Koost. A. Parman. 1997.

http://sool.ioc.ee/ alland/kogudus/stat/maakond.htm

Estonia 1997 = Estonia in Facts: Religion in Estonia. The Estonian Institute. Tallinn.

Kui kristlik 1997 = Kui kristlik on Eestimaa? Koost. N. Roeder, M. Uudam, A. Parman. Eesti

Evangelisatsiooni Allianss.

Kurg, Ingmar 1995. Kristlikud uskkonnad ja organisatsioonid tänapäeva Eestis. J. Gnadenteich.

Kodumaa kirikulugu: usuõpetuse õpperaamat. Tallinn, lk 115-125.

Leppik, Jaan J. 1992. Uususundid Eestis. Vikerkaar, nr 6, 1k 52-57.

Philipp, Guntram 1974. Die Wirksamkeit der herrnhuter Brüdergemeinde unter den Esten und

Letten zur Zeit der Bauernbefreiung (vom Ausgang des 18. bis über die Mitte des 19. Jhs.).

Forschungen zur internationalen Sozial- und Wirtschaftsgeschichte. Bd 5. Köln \& Wien.

Ritsbek, Heigo 1996. The Mission of Methodism in Estonia. Project Thesis. Boston. (Käsikiri Eesti Rahvusraamatukogus).

UNVA = Nõukogude Sotsialistlike Vabariikide Liidu Ministrite Nõukogu juures asuva

Usukultusasjade Nõukogu Voliniku ENSV s arhiiv (1945-1990). Eesti Vabariigi

Siseministeeriumis.

\section{Kommentaarid}

1. Muudetud kujul võeti «Eesti kirikute, koguduste ja koguduste liitude registri põhimäärus» Eesti Vabariigi valitsuse poolt vastu 02. 05. 1996 (vt Riigi Teataja I, nr 32, 1996, art 638).

2. Siseministeeriumis registreeritud usuühenduste nimekirja vt Au \& Ringvee 2000: 132-138.

3. Enam on artikli jaoks materjali pakkunud Leppik 1992; Kurg 1995; Eesti Kirikute Nõukogu, nr 1, 1997; Kui kristlik 1997; Eesti Kristlikud 1997; Eesti ettevõtete 1997: 895-897. Osa neist käsitlustest ja andmekogudest on toetunud peamiselt usuasjade osakonna andmetele ning jäävad viimaste puudulikkuse tõttu sageli lünklikuks. Seetôttu on tulnud kasutada ka sellist mitte eriti usaldusvärrset allikat nagu telefoniraamat, mis andis lisainformatsiooni Eestis tegutsenud registreerimata usuühenduste kohta. Reeglina on telefoniraamatus ilmunud andmed usuorganisatsiooni kohta (nimi, aadress ja telefon) koostajatele andnud vastava organisatsiooni esindaja(d). Samas ei sisaldu sellelaadses allikas need usuühendused, millel pole telefoni või mis mingil muul põhjusel ei ole telefoniraamatus. Lisaks pole välistatud, et mõne usuorganisatsiooni nime taga võis peituda ka (veel) ilma poolehoidjateta üksikisik.

4. EELK 166 kogudusest asus üks Petseris. Lisaks tegutses veel kolm diasporaakogudust väljaspool Eestit.

5. Need andmed erinevad Ilmo Au ja Ringo Ringvee esitatutest, mille järgi olnud 2000. aastaks 
kirikuregistrisse kantud seitse Rooma-Katoliku Kiriku kogudust, kolm nunnaordut ja üks mungaordu - Dominikaani Vendade Ordu Eestis (2000: 15-16).

6. Algselt on Jehoova tunnistajad tegutsenud teiste nimede all: Vahitorni ja Piibli Traktaatide Selts, Tõeliste Piibliuurijate Rahvusvaheline Ühendus.

7. Lisaks on aktiivse misjonitööga silmapaistvatel mormoonidel Eestis tegutsemas veel vähemalt kaks registreerimata kogudust (Au \& Ringvee 2000: 78).

8. Neist kuulsaimaks sai aastatel 1883-1962 elanud Karl Tõnisson (Karlis Tennisons) ehk Vend Vahindra. Aastatel 1984-1988 tegutses Eestimaa Budistlik Vennaskond ja 1980. aastate lõpul loodi Eesti Budistlik Liit, millest kasvasid välja ka nimetatud budistlikud kogudused. Idast pärinevate maailmausunditega seotud kogudustest Eestis vt Au \& Ringvee 2000: 100-107.

9. UNVA andmetel registreeriti seitsmenda päeva baptistide kogudus Eestis juba 1989. aastal. 1990. aastatel pole neid aga selle nime all kirikuregistrisse kantud. Nõukogude perioodil on Eestis illegaalselt tegutsenud ka jehovistid ehk kogudused, mis on teatud erimeelsuste tõttu distantseerunud teistest Jehoova tunnistajatest.

10.Vt ka Kurg 1995: 123-125; Ritsbek 1996: 182 jj; Au \& Ringvee 2000: 113-116, 137-138. 